\section{A comparison between the prevalence of gastroesophageal reflux disease among South- Western Nigerian pregnant women to that of the non- pregnant ones}

\author{
Abiodun Christopher Jemilohun, ${ }^{1}$ \\ Aramide Mikhail Tijani, ${ }^{2}$ \\ Adeniyi Olanipekun Fasanu ${ }^{3}$ \\ ${ }^{1}$ Department of Medicine, Ladoke \\ Akintola University of \\ Technology/LAUTECH Teaching Hospital, \\ Ogbomoso, Oyo State; ${ }^{2}$ Department of \\ Obstetrics and Gynaecology, Ladoke \\ Akintola University of Technology \\ Teaching Hospital, Osogbo, Osun State; \\ ${ }^{3}$ Department of Obstetrics, Gynaecology \\ and Perinatology, Ladoke Akintola \\ University of Technology Teaching \\ Hospital, Ogbomoso, Oyo State, Nigeria
}

\section{Abstract}

Gastroesophageal reflux disease (GERD) is common in the general population. Pregnancy is known to be associated with high incidence of GERD symptoms. Although, there are previously conducted studies involving both genders to determine the prevalence of GERD in different population groups in Nigeria, our preliminary literature search showed that there is a dearth of data on the prevalence of GERD among Nigerian pregnant women. The aim of this study is to determine the prevalence of GERD using the GerdQ questionnaire and to test the association between pregnancy and GERD among women of south-western Nigeria. The study was a descriptive hospital based cross-sectional survey involving three medical facilities in two states of south-western Nigeria. A total of 796 women consisting of $413(51.9 \%)$ healthy pregnant women at various gestational ages and 383 (48.1\%) nonpregnant women were interviewed. A predesigned questionnaire consisting of sociodemographic data, obstetrics information, the GerdQ questionnaire and previous history of GERD symptoms was administered to each of the participants. Of the 796 women interviewed, 413 (51.9\%) were pregnant women with a mean of $27.42( \pm 5.00)$ years and 383 (48.1\%) non-pregnant women of child bearing age with a mean of $26.72( \pm 6.46)$ years. The prevalence of GERD among the pregnant women was $14.5 \%$ while that among the nonpregnant group was $9.7 \%$. This difference was statistically significant $(\mathrm{P}=0.036)$. Following adjustment for potential confounders, pre- gnancy maintained a positive statistically significant relationship with GERD [OR=1.67 (95\% $\mathrm{CI}=1.07,-2.61), \mathrm{P}=0.023$ ]. GERD has a moderate prevalence in pregnancy in southwestern Nigeria. Pregnancy has a significant association with GERD, independent of the other risk factors.

\section{Introduction}

Gastroesophageal reflux disease (GERD) is common in the general population. The disorder affects approximately $10-20 \%$ at least weekly in the Western world. ${ }^{1}$

Pregnancy is known to be associated with high incidence of GERD symptoms with prevalence that ranges between 30 and $80 \%$ in previous studies. ${ }^{2-5}$

Although there are previously conducted studies involving both genders to determine the prevalence of GERD in different population groups in Nigeria, our preliminary literature search showed that there is paucity of data on the prevalence of GERD among Nigerian pregnant women. We found only two studies that evaluated the prevalence of pregnancy related heartburn among pregnant women in Nigeria. ${ }^{6,7}$ The first study was conducted by Bassey in 1977 who found a prevalence of $9.8 \%$ among Nigerian women and $78.8 \%$ among a Caucasian female group. ${ }^{6}$ Audu and Mustapha in 2006 evaluated gastrointestinal symptoms in pregnancy and obtained a $45 \%$ prevalence for heartburn among pregnant women of north-eastern Nigeria. ${ }^{7}$ We previously reported a prevalence of 19.0 and $28.3 \%$ for GERD's typical symptoms of regurgitation and heartburn respectively in a study that evaluated the prevalence of pregnancy related gastrointestinal symptoms. ${ }^{8}$ It is important to note that these cited studies were not conducted with validated standard GERD survey instruments.

Pregnancy related GERD results from the physiological and anatomical changes of pregnancy. These include reduced lower esophageal sphincter pressure and altered gastrointestinal transit engendered by increased maternal estrogen and progesterone, and increased intra-abdominal pressure due to the gravid uterine enlargement. ${ }^{3,9}$

There are several validated patient-centered symptoms analyses-based questionnaires with varying degrees of accuracy designed to assess GERD. ${ }^{10}$ Symptoms analyses method is a practical and inexpensive approach to GERD's diagnosis because it eliminates the need for costly diagnostic procedures such as upper gastrointestinal endoscopy and 24 hour gastric acid monitoring in most patients presenting with the typical symptoms of GERD who have no alarm symptoms. ${ }^{11}$ The GerdQ questionnaire is a validated simple patient-centered
Correspondence: Abiodun Christopher Jemilohun, Department of Medicine, LAUTECH Teaching Hospital, P.M.B. 4007, Ogbomoso, Oyo State, Nigeria.

Tel.: +234.803.867.4623.

E-mail: chrislohun2010@hotmail.com

Key words: Gastroesophageal reflux disease; pregnancy; prevalence; women; Nigeria.

Contributions: ACJ, study conception and design, data collection, data analysis and manuscript writing. AMT, study design, data collection and manuscript review; AOF, study design, data collection and manuscript review.

Conflict of interest: the authors declare no poten tial conflict of interest.

Received for publication: 19 December 2015 Accepted for publication: 14 January 2016.

This work is licensed under a Creative Commons Attribution NonCommercial 4.0 License (CC BYNC 4.0).

(C) Copyright A.C. Jemilohunet al., 2016 Licensee PAGEPress, Italy

Gastroenterology Insights 2016; 7:6373 doi:10.4081/gi.2016.6373

questionnaire which has a diagnostic accuracy similar to that of a gastroenterologist. ${ }^{11-13}$ The contents of the questionnaire are consistent with the Montreal definition and classification of GERD as articulated in a global evidencebased consensus. ${ }^{14}$

The aims of this study were to determine the prevalence of GERD using the GerdQ questionnaire and to test the association between pregnancy and GERD among women of southwestern Nigeria. It is our hope that the information obtained will help in appreciating the burden of this disorder in our environment.

\section{Materials and Methods}

The study was a descriptive hospital based cross-sectional survey. Ethical clearance was obtained from the institution Ethical Review Committee. Written informed consent was also obtained from the participants. A total of 796 women were recruited for the study from October 2014 to March 2015. Subjects consisted of 413 (51.9\%) healthy pregnant women aged 18 and above at various gestational ages attending the antenatal clinics of two healthcare facilities in Oyo State (LAUTECH Teaching Hospital, Ogbomoso and Primary Health Center, Oja-Igbo, Ogbomoso) and one facility in Osun State (LAUTECH Teaching 
Hospital, Osogbo). The three centers are all located in the south-western part of Nigeria. The control population consisted of 383 (48.1\%) non-pregnant women aged 18-45 years recruited from the outpatient departments of the study sites. Individuals with proven history of abdominal cancer, gross ascites and recent abdominal surgery were excluded. A 19-item predesigned questionnaire consisting of socio-demographic data (9 items), obstetrics information (2 items), the GerdQ questionnaire (6 items) and previous history of GERD symptoms (2 items) were administered to each of the participants by well-trained research assistants. The Body Mass Index (BMI) of each subject was calculated by dividing the weight in kilogram by the square of the height in meters. Only essential study staff members were allowed access to the information obtained from participants. All information and data obtained from the participants were treated with utmost confidentiality. Data were analyzed with IBM-Statistical Package for the Social Sciences (IBM-SPSS), version 20. Continuous variables were presented as means \pm SD. Means were compared with Independent Student T Test. Categorical variables were expressed as frequencies and percentages. Differences between categorical variables were compared using Pearson Chisquare test or Fisher exact test as occasion demanded. Binary logistic regressions were performed to test the strength of the relationships between independent variables (risk factors) and GERD (dependent variable). The Variables with odds ratio $(\mathrm{OR})>1$ and $\mathrm{P} \leq 0.05$ were considered as significant risk factors. Confidence Interval (CI) of $95 \%$ was used.

\section{The GerdQ Questionnaire}

The GerdQ questionnaire contains 6 questions with symptoms frequency score (counted in days) of 0 to 3 and a one week period for symptoms recall. It comprises of four positive predictors of GERD, heartburn and regurgitation (the two major reflux symptoms), sleep disturbance because of the two reflux symp- toms and use of over the counter (OTC) medication in addition to that prescribed; and two negative predictors of GERD, epigastric pain and nausea. Scores ranging from 0 to 3 apply for the positive predictors and from 3 to 0 (reversed order, where $3=$ none) apply for negative predictors. The GerdQ score is calculated as the sum of these scores, giving a total score ranging from 0 to 18 .

The GerdQ can be used to diagnose GERD with diagnostic accuracy similar to that of the gastroenterologist at a cut-off of 8 out of 18 points [specificity (71.4\%) and sensitivity (64.6\%)], assess the relative impact of the dis-

Table 1. Socio-demographic and obstetrics characteristics of participants.

\begin{tabular}{|c|c|c|c|}
\hline Variables & Pregnant (\%) & Non-pregnant (\%) & P-value \\
\hline Number of participants & 413 & 383 & - \\
\hline Mean age in years (SD) & $27.42( \pm 5.00)$ & $26.72( \pm 6.46)$ & 0.091 \\
\hline Age range & $18-43$ & $18-45$ & - \\
\hline Mean height in m (SD) & $1.59( \pm 0.07)$ & $1.61( \pm 0.72)$ & 0.001 \\
\hline Mean weight in $\mathrm{kg}(\mathrm{SD}) *$ & $64.99( \pm 11.96)$ & $59.74( \pm 11.85)$ & - \\
\hline BMI in $\mathrm{kg} / \mathrm{m}^{2}$ (SD) & $25.80( \pm 4.53)$ & $23.13( \pm 4.15)$ & - \\
\hline $\begin{array}{l}\text { Educational status } \\
\text { Nil } \\
\text { Primary } \\
\text { Secondary } \\
\text { Tertiary }\end{array}$ & $\begin{array}{c}0.0(0.0) \\
54.0(13.1) \\
175(42.4) \\
184(44.6)\end{array}$ & $\begin{array}{c}2(0.5) \\
18(4.7) \\
109(28.5) \\
254(66.3)\end{array}$ & $<0.0001$ \\
\hline $\begin{array}{l}\text { Ethnicity } \\
\text { Yoruba } \\
\text { Other tribes }\end{array}$ & $\begin{array}{c}400(96.9) \\
13(3.1)\end{array}$ & $\begin{array}{c}364(95.0) \\
19(5.0)\end{array}$ & 0.193 \\
\hline $\begin{array}{l}\text { Marital status } \\
\text { Single } \\
\text { Married } \\
\text { Divorced/separated }\end{array}$ & $\begin{array}{c}23(5.6) \\
389(94.2) \\
1(0.2)\end{array}$ & $\begin{array}{l}225(58.7) \\
154(40.2) \\
4(1.0)\end{array}$ & $<0.0001^{\circ}$ \\
\hline $\begin{array}{l}\text { Smoking } \\
\text { Yes } \\
\text { No }\end{array}$ & $\begin{array}{c}1(.02) \\
412(99.9)\end{array}$ & $\begin{array}{c}0(0.0) \\
383(100.0)\end{array}$ & $1.000^{\circ}$ \\
\hline $\begin{array}{l}\text { Alcohol } \\
\text { Yes } \\
\text { No }\end{array}$ & $\begin{array}{c}2(0.5) \\
411(99.5)\end{array}$ & $\begin{array}{c}26(6.8) \\
357(93.2)\end{array}$ & $<0.0001$ \\
\hline $\begin{array}{c}\text { Caffeine } \\
\text { Yes } \\
\text { No }\end{array}$ & $\begin{array}{c}44(10.7) \\
369(89.3)\end{array}$ & $\begin{array}{c}83(20.4) \\
300(78.3)\end{array}$ & $<0.0001$ \\
\hline $\begin{array}{c}\text { Gravidity } \\
1 \\
2-7\end{array}$ & $\begin{array}{l}129(31.2) \\
284(68.8)\end{array}$ & & \\
\hline $\begin{array}{l}\text { Current trimester } \\
\text { 1st } \\
\text { 2nd } \\
\text { 3rd }\end{array}$ & $\begin{array}{c}21(5.1) \\
150(36.3) \\
242(58.6)\end{array}$ & & \\
\hline
\end{tabular}

*weight at time of survey, ${ }^{\circ}$ Fisher exact test.

Table 2. Frequency of gastroesophageal reflux disease symptoms among pregnant $(n=413)$ and non-pregnant women ( $=383)$, all values given in $\%$.

\begin{tabular}{|c|c|c|c|c|c|c|c|c|c|c|c|}
\hline \multirow[t]{3}{*}{ Symptoms } & \multirow{2}{*}{\multicolumn{2}{|c|}{0 day }} & \multirow{2}{*}{\multicolumn{2}{|c|}{ 1day }} & \multirow{2}{*}{\multicolumn{2}{|c|}{$\begin{array}{l}\text { Frequency } \\
\text { 2-3 days }\end{array}$}} & \multirow{2}{*}{\multicolumn{2}{|c|}{ 4-7 davs }} & \multirow{2}{*}{\multicolumn{2}{|c|}{ Total Positive }} & \multirow[t]{3}{*}{ P value } \\
\hline & & & & & & & & & & & \\
\hline & P & NP & P & NP & $\mathbf{P}$ & NP & $\mathbf{P}$ & NP & $\mathbf{P}$ & NP & \\
\hline Heartburn* & 78.2 & 83.0 & 8.7 & 9.4 & 6.8 & 5.2 & 6.3 & 2.3 & 21.8 & 17.0 & 0.037 \\
\hline Regurgitation* & 85.5 & 88.3 & 5.3 & 7.8 & 4.6 & 2.6 & 4.6 & 1.3 & 14.5 & 11.7 & 0.011 \\
\hline Epigastric pain ${ }^{\circ} \#$ & 82.1 & 81.2 & 4.8 & 4.7 & 6.3 & 5.0 & 6.8 & 9.1 & 17.9 & 18.8 & 0.562 \\
\hline Nausea \# & 73.6 & 78.6 & 7.5 & 7.3 & 6.1 & 7.0 & 12.8 & 7.0 & 26.4 & 21.4 & 0.056 \\
\hline Sleep disturbance* & 91.5 & 95.0 & 2.7 & 3.1 & 3.9 & 1.3 & 1.9 & 0.5 & 8.5 & 5.0 & 0.036 \\
\hline OTC drugs* & 95.6 & 93.2 & 1.0 & 3.4 & 2.4 & 1.6 & 1.0 & 1.8 & 4.4 & 6.8 & 0.061 \\
\hline
\end{tabular}

P, Pregnant; NP, Non-pregnant; *Positive GERD predictor; ${ }^{\circ}$ Received reverse scores in the questionnaire; ${ }^{\circledR}$ Negative GERD predictors. 
ease on patients' lives, to assist in choice of treatment and measure response to treatment over time.

\section{Results}

Table 1 shows the demographic and obstetrics characteristics of respondents. A total of 796 women were interviewed, out of which 413 (51.9\%) were pregnant women (subjects) and 383 (48.1\%) non-pregnant women of childbearing age (controls). The age range of the pregnant women was 18-43 years with a mean of $27.42( \pm 5.00)$ years; whereas the age range of the controls was 18-45 years with a mean of $26.72( \pm 6.46)$ years. There was no statistically significant difference in age between the two populations $(\mathrm{P}=0.091)$. There was significant difference between the height of the pregnant and the non-pregnant group ( $\mathrm{P}=0.001)$. While the pregnant group had a mean height of 1.59 $( \pm 0.07)$ meters, the non-pregnant group had a mean height of $1.61( \pm 0.72)$ meters. We could not compare the weight and the BMI of the two groups because we did not get the pre-pregnancy weight of the pregnant women. It is often difficult for pregnant women in this environment to give their pre-pregnancy weight with absolute certainty. More often than not, the weight at booking, which usually takes place in the late first trimester/second trimester in this environment, is often recorded for future comparison.

The two groups differ significantly in terms of formal education attainment $(\mathrm{P}<0.001)$. While majority of both groups had at least secondary school education (87\% of pregnant and $94.8 \%$ of non-pregnant), more of the latter (66.3\%) had tertiary education compared to the former (44.6\%).

Majority of the participants in both groups were of Yoruba ethnic group from the southwestern part of Nigeria. A total of 96.9 and $95.0 \%$ of the pregnant and the non-pregnant group respectively were Yoruba. This relationship was not statistically significant.

Though, majority of the pregnant group was married (94.2\%), less than half of the nonpregnant group was (40.2\%). There was a statistical difference between the marital status of the two groups $(\mathrm{P}<0.0001)$.

In regard to the social habits with proven relationship with GERD, only $1(0.2 \%)$ of the pregnant group smoked cigarette, none of the non-pregnant participants did. This relationship was not statistically significant $(\mathrm{P}=1.00)$. Whereas $0.5 \%$ of the pregnant women regularly took alcohol as at the time of the interview, $6.8 \%$ of the non-pregnant indulged the habit. This relationship was statistically significant $(<0.0001)$. The two groups also differ significantly in term of consumption of caffeine con-
Table 3. GerdQ Scores and Prevalence of gastroesophageal reflux disease (GERD) among pregnant $(n=413)$ and non-pregnant women $(n=383)$.

\begin{tabular}{lccc} 
Variables & \multicolumn{2}{c}{ Preginancy status } & P value \\
& Pregnant (\%) & Non-pregnant (\%) & 0.037 \\
GERD score group & & & \\
$0-2$ & $14(3.4)$ & $26(6.8)$ & \\
$3-7$ & $339(82.1)$ & $28(83.6)$ & \\
$8-10$ & $46(11.1)$ & $9(2.3)$ & 0.036 \\
$11-18$ & $14(3.4)$ & & \\
GERD status & & $37(9.7)$ & \\
Positive & $60(14.5)$ & $346(90.3)$ & \\
Negative & $353(85.5)$ & & \\
\hline
\end{tabular}

Table 4. Unadjusted and adjusted risk factors for women to have gastroesophageal reflux disease $(n=796)$.

\begin{tabular}{lcccc} 
Risk factor & $\begin{array}{c}\text { Positive } \\
\text { for GERD (\%) }\end{array}$ & $\begin{array}{c}\text { Unadjusted } \\
\text { odds ratio }\end{array}$ & $\begin{array}{c}\text { Adjusted } \\
\text { odds ratio }\end{array}$ & $\begin{array}{c}\text { P value } \\
\text { Pregnancy }\end{array}$ \\
$\quad$ No $(\mathrm{n}=383)$ & $37(9.7)$ & 1 (Reference) & & 0.023 \\
$\quad$ Yes $(\mathrm{n}=413)$ & $60(14.5)$ & $1.59(1.03-2.46)$ & $1.67(1.07-2.61)$ & \\
Caffeine & $77(11.5)$ & 1 (Reference) & & 0.063 \\
No $(\mathrm{n}=669)$ & $20(15.7)$ & $1.44(0.84-2.45)$ & $1.68(0.97-2.91)$ & \\
Yes $(\mathrm{n}=127)$ & $97(12.2)$ & $1.03(1.0-1.07)$ & $1.03(1.00-1.07)$ & 0.078 \\
\hline Age $(\mathrm{n}=796)$ & & &
\end{tabular}

Table 5. Relationship between current body mass index (BMI) and gastroesophageal reflux disease (GERD) in pregnant and non-pregnant women.

\begin{tabular}{cccc} 
Current BMI & Positive for GERD (\%) & Odds ratio & P value \\
Non-pregnant $(\mathrm{n}=383)$ & & & 0.017 \\
$\leq 24.99(\mathrm{n}=289)$ & $22(7.6)$ & 1 (Reference) & \\
$\geq 25.00(\mathrm{n}=94)$ & $15(16.0)$ & $2.30(1.14-4.65)$ & 0.241 \\
Pregnant $(\mathrm{n}=413)$ & & & \\
$\leq 24.99(\mathrm{n}=201)$ & $25(12.4)$ & 1 (Reference) & \\
$\geq 25.00(\mathrm{n}=212)$ & $35(16.5)$ & $1.39(0.80-2.42)$ & \\
\hline
\end{tabular}

Table 6. Predictors of gastroesophageal reflux disease (GERD) in pregnancy $(n=413)$.

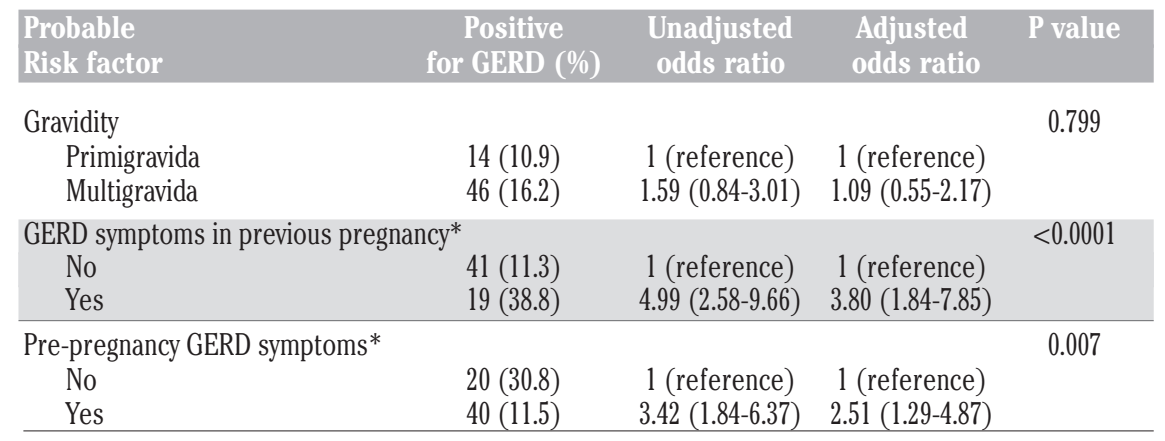

*Heartburn and regurgitation.

Table 7. Gastroesophageal reflux disease (GERD) impact on suffers' lives ( $n=796)$.

\begin{tabular}{|c|c|c|c|}
\hline \multirow[t]{2}{*}{ Pregnancy status } & \multicolumn{2}{|c|}{ GERD impact } & \multirow[t]{2}{*}{ P value } \\
\hline & High (\%) & Low $(\%)$ & \\
\hline Pregnant $(\mathrm{n}=60)$ & $14(23.3)$ & $46(76.7)$ & 0.571 \\
\hline Non-pregnant ( $\mathrm{n}=37)$ & $11(29.7)$ & $26(70.3)$ & 0.571 \\
\hline
\end{tabular}


taining substances (coffee and kola nut). While $10.7 \%$ of the pregnant subjects consumed caffeine, $20.4 \%$ of the non-pregnant group did $(\mathrm{P}<0.0001)$. Pregnant subjects' gravidity (number of pregnancies till date) ranged from 1-7 with a median of 2 . Of the 413 pregnant subjects, 129 (31.2\%) were having their first pregnancies, while 284 (68.8\%) were having their $2^{\text {nd }}$ to $7^{\text {th }}$ pregnancies. More than half of the pregnant subjects were in their third trimester [242 (58.6\%)], 150 (36.3\%) were in their second trimester, only 20 (4.8\%) were in their first trimester.

Table 2 shows the frequencies of the symptoms of GERD among the pregnant and the non-pregnant women. Of the four positive predictors of GERD (heartburn, regurgitation, sleep disturbance because of the two reflux symptoms and use of OTC medication), heartburn had the highest occurrence among both groups (21.8\% pregnant women and $17.0 \%$ non-pregnant respectively suffered from the symptom at least one day in the last week of their lives). This relationship was statistically significant $(\mathrm{P}=0.037)$. While use of OTC medication had the least occurrence of the positive GERD predictors among the pregnant group (4.4\%), sleep disturbance was the least occurring positive predictor among the non-pregnant group (5.0\%). Of the two negative symptoms recorded (epigastric pain and nausea), nausea had the highest occurrence in both population groups with the pregnant group (26.4\%) having a higher frequency than the non-pregnant (21.4\%). All symptoms evaluated recorded more occurrence in the pregnant group than in the non-pregnant group, except epigastric pain (17.9\% vs. $18.8 \%)$ and use of OTC drugs (4.4\% vs. $6.8 \%$ ). Whereas the relationship between pregnant and non-pregnant women of the frequencies of heartburn $(\mathrm{P}=0.037)$, regurgitation $(\mathrm{P}=0.011)$ and sleep disturbance $(\mathrm{P}=0.36)$ were statistically significant, the other symptoms had no statistically significant relationships between the two groups.

After the GERD scores were computed (Table 3), $14.5 \%$ of the pregnant women were diagnosed of GERD (scored between 8 and 18) while $9.7 \%$ of the non-pregnant group qualified for GERD diagnosis. The difference in the prevalence of GERD among the pregnant group and the non-pregnant one was statistically significant $(\mathrm{P}=0.036)$. Majority of the participants in both groups fell within the 3-7 GERD score range (pregnant $82.1 \%$ and non-pregnant 83.6\%).

A binary logistic regression model was created in order to eliminate the effect of possible confounders on the strength of the association of pregnancy with GERD among the women (Table 4). The dependent variable was GERD while the independent variables (risk factors) were pregnancy, consumption of caffeine and age. Cigarette smoking was not included in the model because only one of the participants (a pregnant woman) indulged the habit (Table 1). Alcohol consumption was also not included because it had no significant impact on GERD in the preliminary analysis [OR=0.55 $(95 \%$ $\mathrm{CI}=0.13-2.33), \mathrm{P}=0.413$ ]. Following adjustment for potential confounders, pregnancy maintained a positive statistically significant relationship with GERD [OR=1.67 (95\% $\mathrm{CI}=1.07-2.61), \mathrm{P}=0.023$ ]. Both age and consumption of caffeine did not have statistically significant relationships with GERD.

Table 5 shows the BMI of the participants at the time of the survey (current BMI), classifying them into the underweight/normal (BMI $\geq 24.99$ ) and the overweight/obese groups (BMI $\geq 25.00$ ). Increased BMI in the non-pregnant group was positively related to GERD [OR=2.30 (95\% $\mathrm{CI}=1.14-4.65), \mathrm{P}=0.017]$. That is, non-pregnant women with overweight/ obese BMI are 2.3 times more likely to develop GERD than the ones with underweight/normal BMI. Increased BMI in the pregnant group had no statistically significant relationship with GERD $\quad[\mathrm{OR}=1.39 \quad(96 \% \quad \mathrm{CI}=0.80-2.42)$, $\mathrm{P}=0.241]$.

Another binary logistic regression model was created to test the strength of the relationships between risk factors that are peculiar to pregnancy with the occurrence of GERD in the pregnant group of the study (Table 6). After a preliminary analysis the independent variables included in the model are gravidity, GERD symptoms (heartburn and regurgitation) in previous pregnancy and Pre-pregnancy GERD symptoms. Multi-gravidity did not have positive significant association with GERD [OR=1.09 (95\% CI=0.55-2.17), $\mathrm{P}=0.799]$. It was observed that the relationships between those who had positive history of heartburn/regurgitation during previous pregnancies or in the period prior to the current pregnancy with the occurrence of GERD were statistically significant. Of the 49 pregnant women who had positive history of heartburn/regurgitation during previous pregnancies, $38.8 \%$ of them were diagnosed of GERD [OR=3.80 (95\% CI=1.84-7.85), $\mathrm{P}<0.0001$ ]. Also, $30.8 \%$ of 65 pregnant women who had pre-pregnancy history of heartburn/regurgitation were diagnosed of GERD at the time the survey was carried out [OR=2.51 (95\% $\mathrm{CI}=1.29-4.87), \mathrm{P}=0.007]$.

The GerdQ questionnaire has an additional feature of being able to identify the impact of GERD on the lives of the sufferers. Patients with a total score of $\geq 3$ out of 6 on sleep disturbance plus OTC medication use are those most likely to be highly impacted by their disease. ${ }^{11}$ The impact of GERD on the lives of the sufferers was tested through a layered Chi-square test with GERD status as the divider (Table 7). While $23.3 \%$ of the 60 GERD patients among the pregnant group were highly impacted by the disease, $29.7 \%$ of the 37 non-pregnant GERD patients were. This relationship was not statistically significant $(\mathrm{P}=0.484)$.

\section{Discussion}

It has been previously shown that the frequency of GERD rises considerably during pregnancy, with $30-80 \%$ of all pregnant women suffering from GERD at some time during pregnancy. ${ }^{2-6}$ This is often associated with a deterioration in the quality of life of the pregnant women. ${ }^{15,16}$

We obtained a GERD prevalence of $14.5 \%$ among pregnant women as compared to $9.7 \%$ among the non-pregnant ones and this relationship was statistically significant $(\mathrm{P}=0.36)$. Following adjustment for potential confounders, pregnancy remained positively related to the development of GERD (Table 4). This finding confirms that pregnancy has a positive association with the development of GERD in the south-western Nigerian population like in other parts of the world. The implication of this is that Nigerian pregnant women of southwestern origin are 1.6 times more likely to develop GERD than the ones that are not pregnant.

A comparison with similar studies from other parts of the world showed that the prevalence of GERD in pregnant women from our study was lower. Ramu and colleagues, in a southern state of the Indian subcontinent obtained a prevalence of $45.5 \%$ from a crosssectional study. Rey and colleagues obtained a prevalence of $59.3 \%$ at any time during pregnancy and an incidence of approximately $25 \%$ in each trimester of gestation in a prospective longitudinal study in a Spanish population. Malfertheiner and colleagues, also in a prospective longitudinal study conducted in a German population, found a GERD prevalence of $26.1 \%$ in the first trimester, $36.1 \%$ in the second trimester and $51.2 \%$ in the third trimester of pregnancy and $9.3 \%$ in the nonpregnant women. Our finding is, however, in keeping with Bassey's previous finding of heartburn prevalence of $9.8 \%$ among Nigerian pregnant women as compared to $78.8 \%$ in Caucasian pregnant/post-natal women. It has been postulated that the higher prevalence of GERD symptoms in pregnant Caucasian as compared to Black Africans living in Africa may be as a result of consumption of lowresidue diet by the Caucasians that predisposes them to constipation with straining at stool and consequent displacement of the lower esophageal sphincter into the thorax as opposed to the latter that tend to adhere to their traditional high-residue high-carbohydrate diet. ${ }^{6}$ 
We could not find any recent study that was specifically conducted to determine the prevalence of GERD among pregnant women in Nigeria in strict compliance with the Montreal definition for comparison. However, a study that evaluated the prevalence of heartburn and other gastrointestinal symptoms among pregnant Nigerians living in Nigeria in 2005 and a study we previously conducted yielded heartburn prevalence rates of $45 \%$ and $28.3 \%$ respectively. ${ }^{7,8}$ We obtained prevalence rates of $21.8 \%$ and $17.0 \%$ respectively for heartburn alone occurring at least once in a week for the pregnant group and the non-pregnant one in this study (Table 2). The lower prevalence of GERD as determined by the GerdQ in this study as compared to those of heartburn alone in this study and the cited ones implies that some of the participants most likely had occasional heartburn that did not qualify to be diagnosed as GERD.

Several studies in various populations have demonstrated other risk factors for GERD, apart from pregnancy. These include age, obesity, tobacco smoking, alcohol consumption, intake of caffeine containing substances, diet etc. ${ }^{17-21}$ The consumption of caffeine containing substances, namely coffee and kola nut, did not have a statistically significant effect on the occurrence of GERD among the participant according to our study. This finding is contrary to that of a previous study by Nwokediuko in the south-eastern part of Nigeria who reported a positive relationship between the consumption of coffee and Kola nut with GERD. ${ }^{20,22}$ The reason for this disparity may be adduced to the fact that a higher percentage of Nwokediuko's study participants consumed caffeine containing substances than the participants in our study. Moreso, Nwokediuko's study involved both male and female genders. Males generally consume more of these substances in our environment. The association between cigarette smoking and alcohol consumption with GERD could not be reliably tested statistically in our study because very few of the participants consumed these products. This finding is likely to be because consumption of these social drugs by the female gender is often frowned at in the tradition south-western Nigerian (Yoruba) setting. Females who consume alcohol or cigarette are often regarded as the wayward type, hence, the abstinence from the products or the non-disclosure of consumption. Our study did not show a statistically significant association between increasing age and GERD. This is in tandem with Nwokediuko's finding of no significant relationship between increasing age and GERD in the south-eastern part of Nigeria, but contrary to the finding of Du and colleagues in China who observed a rising incidence of GERD with increasing age. ${ }^{22,23}$ The reason for this contradiction may be the fact that most of the partici- pants in ours and Nwokediuko's study were in their third and fourth decades of life. A similar study in a more diverse population with broader age range will likely demonstrate the effect of age more appropriately. Our observation of a significant association of increased BMI with GERD in the non-pregnant group of this study is contrary to the finding of no significant relationship between increased BMI and GERD in a previous hospital based study conducted in the south-western part of Nigeria among adult male and female population. ${ }^{24}$ This disparity may not be unconnected to the fact that our study considered only the female gender and had a restricted age range of $18-45$ years as compared to the said study that included a wider age range and both genders. However, our finding is in tandem with several other studies from outside Nigeria that showed a positive relationship between increased BMI and GERD in the adult population. ${ }^{25-27}$

We did not find a positive association between increased BMI in the pregnant women and the occurrence of GERD. However, Rey and colleagues in a previous study found a positive relationship between cumulative weight gain in the third trimester with GERD with no such association in the first and second trimesters of the pregnant women. ${ }^{28}$ Our observation may be an indication that the weight/BMI at the time of survey is not the best option in evaluating the effect of weight gain during pregnancy on the development of GERD. Rather, the weight/BMI before conception should be obtained where possible in order to allow for proper comparison. Our finding of a positive significant relationship between GERD symptoms in previous pregnancies and the occurrence of GERD in the pregnant group of our study and a previous finding by Bor and colleagues of an increased risk of GERD after pregnancy by the presence of heartburn during previous pregnancies, independent of age and obesity, ${ }^{29}$ further corroborates the fact that pregnancy related GERD symptoms may not be an innocent or a transient condition. Our observation of a significant relationship between heartburn and/or regurgitation during the period preceding pregnancy is in consonance with the finding of such association in the first and third trimester of pregnancy by Rey and colleagues. ${ }^{28}$ This implies that pregnancy does not have ameliorating effect on previously developed symptoms of GERD. Of the participants who suffered from GERD, $23.3 \%$ of the pregnant group and $29.9 \%$ of the non-pregnant group respectively were highly impacted by the ailment. This is worthy of note in that about a quarter and a third respectively of the pregnant and the nonpregnant sufferers had a severe form of the disease. Drugs are often cautiously used during pregnancy because of the fear that they may have teratogenic effect on the unborn child. The standard recommended medication for the treatment of GERD in the non-pregnant population is proton pump inhibitors (PPIs), which are very effective and well tolerated. However, a stepwise management approach is recommended in the pregnant population. ${ }^{9,16}$ Important recommendations in a progressive order in the management of pregnancy related GERD include: lifestyle modification, the use of antacids, histamine-2 receptors antagonists, and the use of PPIs. ${ }^{9,16}$ Gastroesophageal reflux symptoms in pregnancy can be managed by lifestyle modification and the use of antacids as may be required. Nevertheless, women with severe symptoms should be treated with PPIs as it the most effective among all the alternatives. Physicians often shy away from prescribing PPIs to pregnant women because of assumed potential teratogenic effect. Currently available data, however, suggest that they do not predispose to increased negative fetal outcome. ${ }^{30,31}$ When occasion demands, the physician may need to discuss these medications with the pregnant woman before commencement.

A important limitation of this study is that it is a cross-sectional study. A prospective longitudinal study is desirable in order to evaluate the evolution and incidence of GERD symptoms in all the trimesters of pregnancy in this environment.

\section{Conclusions}

Gastroesophageal reflux disease has a moderate prevalence in pregnancy in south-western Nigeria. Pregnancy has a significant association with GERD, independent of the other risk factors. It is our hope that the data generate will contribute to the body of knowledge on this subject.

\section{References}

1. Dent J. Epidemiology of gastrooesophageal reflux disease: a systematic review. Gut 2005;54:710-7.

2. Malfertheiner SF, Malfertheiner MV, Kropf $\mathrm{S}$, et al. A prospective longitudinal cohort study: evolution of GERD symptoms during the course of pregnancy. BMC Gastroenterol 2012;12:131.

3. Ramu B, Mohan P, Rajasekaran MS, Jayanthi V. Prevalence and risk factors for gastroesophageal reflux in pregnancy. Indian J Gastroenterol 2011;30:144-7.

4. Rey E, Rodriguez-Artalejo F, Herraiz MA, et al. Gastroesophageal reflux symptoms during and after pregnancy: a longitudinal study. Am J Gastroenterol 2007;102:2395- 
400.

5. Ho KY, Kang JY, Viegas OA. Symptomatic gastro-oesophageal reflux in pregnancy: a prospective study among Singaporean women. J Gastroenterol Hepatol 1998;13: 1020-6.

6. Bassey 00. Pregnancy heartburn in Nigerians and Caucasians with theories about aetiology based on manometric recording from the oesophagus and stomach. Br J Obstet Gynaecol 1977;84:439-43.

7. Audu BM, Mustapha SK. Prevalence of gestrointestinal symptoms in pregnancy. Niger J Clin Pr 2006;9:1-6.

8. Jemilohun AC, Fasanu A0, Tijani AM, Olayinka GS. Prevalence of gastrointestinal symptoms and related drug use among pregnant women of South-Western Nigeria. Int J Reprod Contracept Obstet Gynecol 2015;4:1464-70.

9. Richter JE. Heartburn, nausea, vomiting during pregnancy. In: Pregnancy in gastrointestinal disorders. 2nd ed. Am Coll Gastroenterol 2007. pp 18-25.

10. Mouli VP, Ahuja V. Questionnaire based gastroesophageal reflux disease (GERD) assessment scales. Indian J Gastroenterol 2011;30:108-17.

11. Jones R, Junghard 0 , Dent $J$, et al. Development of the GerdQ, a tool for the diagnosis and management of gastrooesophageal reflux disease in primary care. Aliment Pharmacol Ther 2009;30: 1030-8.

12. Suzuki H, Matsuzaki J, Okada S, et al. Validation of the GerdQ questionnaire for the management of gastro-oesophageal reflux disease in Japan. United Eur Gastroenterol J 2014;1:175-83.

13. Jonasson C, Wernersson B, Hoff DA, Hatlebakk JG. Validation of the GerdQ questionnaire for the diagnosis of gastrooesophageal reflux disease. Aliment Pharmacol Ther 2013;37:564-72.

14. Vakil N, van Zanten SV, Kahrilas P, et al. The Montreal definition and classification of gastroesophageal reflux disease: a global evidence-based consensus. Am J Gastroenterol 2006;101:1900-20.

15. Suzuki S, Dennerstein L, Greenwood KM, et al. Sleeping patterns during pregnancy in Japanese women. J Psychosom Obstet Gynaecol 1994;15:19-26.

16. Richter JE. Review article: the management of heartburn in pregnancy. Aliment Pharmacol Ther 2005;22:749-57.

17. Buttar NS, Falk GW. Pathogenesis of gastroesophageal reflux and barrett esophagus. Mayo Clinnic Proc 2010;76:226-34.

18. Jarosz M, Taraszewska A. Risk factors for gastroesophageal reflux disease: the role of diet. Przeglad Gastroenterol 2014;9:297301.

19. Tutuian R. Adverse effects of drugs on the esophagus. Best Pract Res Clin Gastroenterol 2010;24:91-7.

20. Lee SJ, Jung MK, Kim SK, et al. Clinical characteristics of gastroesophageal reflux disease with esophageal injury in Korean: focusing on risk factors. Korean J Gastroenterol 2011;57:281.

21. Zheng Z, Nordenstedt H, Pedersen NL, et al. Lifestyle factors and risk for symptomatic gastroesophageal reflux in monozygotic twins. Gastroenterology 2007;132:8795.

22. Nwokediuko S. Gastroesophageal reflux disease: a population based study. Gastroenterol Res 2009;2:152-6.

23. Du J, Liu J, Zhang H, et al. Risk factors for gastroesophageal reflux disease, reflux esophagitis and non-erosive reflux dis- ease among Chinese patients undergoing upper gastrointestinal endoscopic examination. World J Gastroenterol 2007;13: 6009-15.

24. Akere A, Adebusoye L, Afolabi B. Association between body mass index and gastroesophageal reflux disease in blacks. Nig J Gastroenterol Hepatol 2010;2:89-94.

25. Murray L. Relationship between body mass and gastro-oesophageal reflux symptoms: the Bristol Helicobacter project. Int $\mathrm{J}$ Epidemiol 2003;32:645-50.

26. El-Serag HB, Graham DY, Satia JA, Rabeneck L. Obesity is an independent risk factor for GERD symptoms and erosive esophagitis. Am J Gastroenterol 2005;100: 1243-50.

27. Hampel H. Meta-analysis: obesity and the risk for gastroesophageal reflux disease and its complications. Ann Intern Med 2005;143:199.

28. Rey E, Rodriguez-Artalejo F, Herraiz MA, et al. Gastroesophageal reflux symptoms during and after pregnancy: a longitudinal study. Am J Gastroenterol 2007;102:2395400.

29. Bor S, Kitapcioglu G, Dettmar P, Baxter T. Association of heartburn during pregnancy with the risk of gastroesophageal reflux disease. Clin Gastroenterol Hepatol 2007;5:1035-9.

30. Gill SK, O'Brien L, Einarson TR, Koren G. The safety of proton pump inhibitors (PPIs) in pregnancy: a meta-analysis. Am J Gastroenterol 2009;104:1541-5.

31. Pasternak B, Hviid A. Use of proton-pump inhibitors in early pregnancy and the risk of birth defects. N Engl J Med 2010;363: 2114-23. 